\title{
Traumatismo cranioencefálico grave em paciente vítima de autoagressão por projétil de arma de fogo
}

\section{Severe Traumatic Brain Injury in Patient Victim of Self-harm by Gunshot Wound}

Gabriela Baltar Ferreira Gomes ${ }^{1} *$, Bruna Barbosa Galindo ${ }^{1}$, Carlos Henrique Monteiro Maciel Lyra ${ }^{2}$, Isabela Paulino Serur ${ }^{1}$, Isabelle Cecília de Vasconcellos Piscoya ${ }^{1}$, Natália Araújo Magalhães Duarte ${ }^{1}$, Rafaela Monteiro Maciel Lyra ${ }^{3}$, Virgínia Monteiro Maciel Lyra ${ }^{1}$, Welliany Bispo de Santana ${ }^{1}$

${ }^{1}$ Faculdade de Ciências Médicas - Universidade de Pernambuco, Recife, Brasil

${ }^{2}$ Faculdade Pernambucana de Saúde, Recife, Brasil

${ }^{3}$ Universidade Católica de Pernambuco, Recife, Brasil

*correspondência: gabrielabaltar96@gmail.com

\section{Resumo}

O Traumatismo Cranioencefálico (TCE) corresponde a 20,6\% dos traumas por projétil de arma de fogo (PAF), levando a uma elevada morbimortalidade. Desses, muitos são resultado da autoagressão, sendo o Brasil o $8^{\circ}$ país em número absoluto de suicídios. O tratamento nesses casos pode ser conservador ou cirúrgico a depender da localização e gravidade das lesões. O presente trabalho relata o caso de paciente jovem, 29 anos, vítima de lesão cerebral por PAF autoinfligida, tendo por objetivo discutir conceitos acerca do tema, bem como, as condutas adotadas.

Palavras-chaves: Traumatismo Cranioencefálico, Suicídio, Neurocirurgia, Projétil de Arma de Fogo.

\begin{abstract}
Traumatic Brain Injury (TBI) is responsible for 20,6\% of the traumas caused by gunshot wounds, leading to high rates of morbidity and mortality. Many of those result are from self-harm and Brazil stands in the $8^{\text {th }}$ position in absolute number of suicide. Treatment in these cases may be whether conservative or surgical, depending on the site and severity of the injuries. This study reports a case of a 29 -year-old female patient who was victim of TBI caused by self-inflicted gunshot wounds. Therefore, the authors aim to discuss some aspects of the theme as well as the management of the brain injury in this case.
\end{abstract}

Keywords: traumatic brain injury, suicide, neurosurgery, gunshot wound.

\section{Introdução}

Com o aumento da violência nos grandes centros urbanos, houve acréscimo na incidência de lesões causadas por Projétil de Arma de Fogo (PAF) no país, correspondendo a $67 \%$ das injúrias penetrantes do corpo. ${ }^{1}$ No caso de Traumatismo Cranioencefálico (TCE), que corresponde a 20,6\% dos traumas por PAF, tem-se como consequências lesões com altas taxas de morbimortalidade. ${ }^{2}$ $\mathrm{O}$ método de imagem mais importante para a avaliação das lesões por PAF é a Tomografia Computadorizada (TC), superior aos exames radiológicos simples, pois permite a visualização de estruturas encefálicas, mais do que elementos ósseos ou fragmentos metálicos. ${ }^{2} \mathrm{O}$ tratamento pode ser conservador ou cirúrgico, a abordagem e técnica irão diferir conforme a gravidade e localização das 
lesões. ${ }^{1}$ Este relato objetiva apresentar o caso de uma paciente vítima de TCE por PAF autoinfligido, discutir conceitos acerca do tema e condutas adotadas, comparando com o que é descrito na literatura científica.

\section{Relato de Caso}

Paciente com 29 anos, sexo feminino, natural e residente de Recife - PE. Foi admitida no Hospital da Restauração (HR), devido a TCE secundário a tentativa de suicídio por PAF de crânio. Ao exame apresentava Escala de Coma de Glasgow $(\mathrm{ECG})=8$, isocoria e foto reação. Foi realizada intubação orotraqueal, e a paciente foi encaminhada para realização de TC de crânio (Figura 1), que demonstrou fratura frontal com afundamento, lesão meningocortical difusa, contusão cerebral e fragmentos ósseos e metálicos em ambos os hemisférios cerebrais, pneumoencéfalo na área de trajeto do projétil, edema axial difuso com linha média levemente desviada para a direita e ventrículo direito parcialmente aparente.

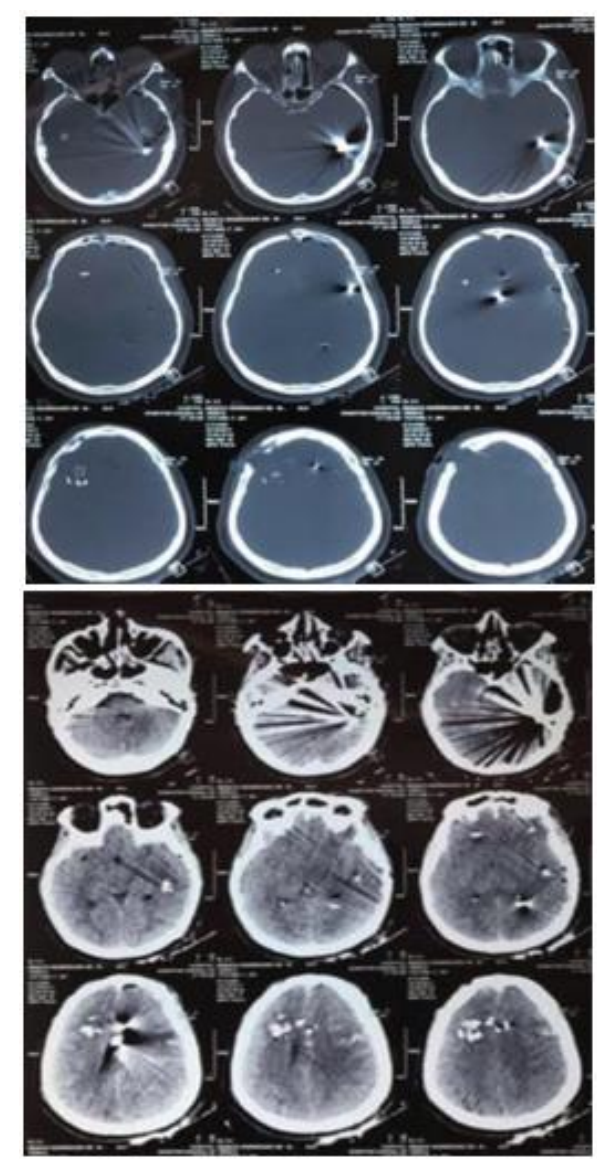

Figura 1. Cortes da Tomografia Computadorizada de crânio evidenciando traumas.

Devido à extensão das lesões, a paciente foi submetida a neurocirurgia de urgência (Figura 2). Foi realizada incisão de pele tipo Kempe, rebatimento de flap miocutâneo, craniectomia frontotemporoparietal à esquerda, sendo evidenciado sangramento em topografia do seio sagital, realizado controle da hemorragia com suspensão dural, patch muscular e Surgicel®. Posteriormente, foi feita durotomia em estrela, revisão de hemostasia e sutura da incisão após aposição de dreno Portovack®. Não foi realizada duroplastia. Em segundo tempo, a fratura craniana por PAF à direita foi abordada, realizou-se ampliação da incisão, remoção de fragmentos ósseos para exposição de bordos durais, drenagem da contusão e hemostasia, duroplastia, aposição de dreno Portovack® e sutura de pele.
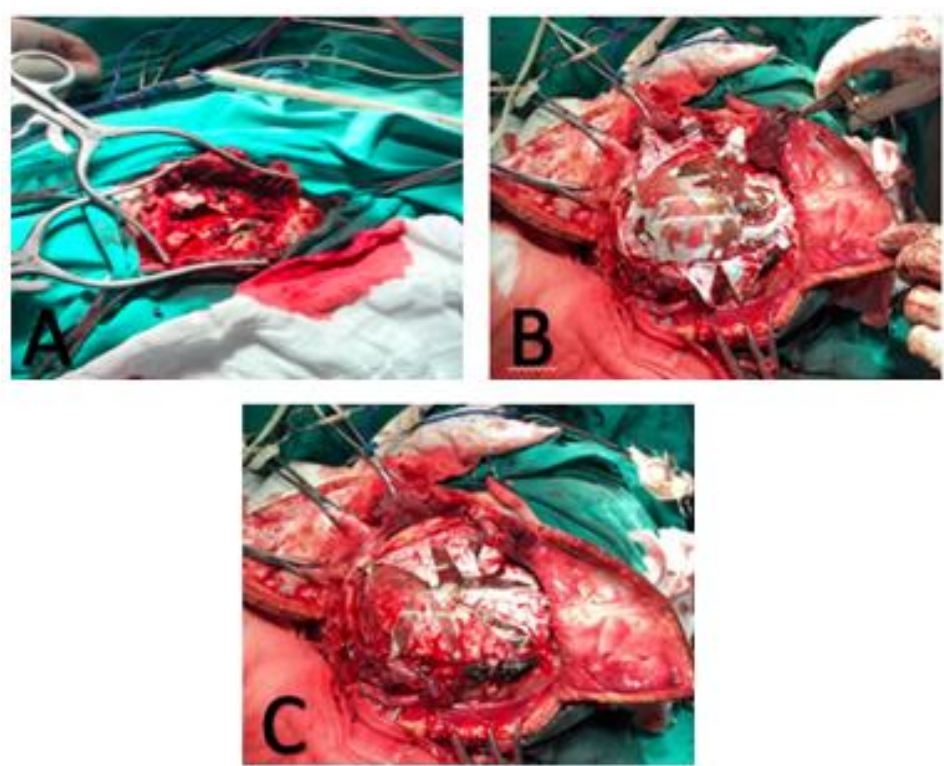

Figura 2. Imagens do intraoperatório em A) fratura craniana por $\mathrm{PAF}$ à direita, em B) e C) durotomia em estrela e hemostasia com patch muscular e Surgicel ${ }^{\circledR}$

Após a cirurgia, a paciente foi admitida na sala de recuperação, onde evoluiu sem intercorrências. Cinco dias depois, foi transferida para a Unidade de Terapia Intensiva (UTI), o desmame da ventilação mecânica ocorreu no $8^{\circ}$ dia pós-operatório. A paciente evoluiu com ECG $=11$, alerta, obedecendo a comandos, com pupilas médias e fotorreagentes. Recebeu alta para a enfermaria de neurocirurgia 17 dias após procedimento cirúrgico.

\section{Comentários}

O Brasil é o $8^{\circ}$ país em números absolutos de suicídio, e apesar da mortalidade ser maior nos homens, as tentativas de suicídio são mais incidentes nas mulheres. É importante salientar que uma das três principais causas de morte em pessoas com idade entre 15-35 anos é a autoagressão. ${ }^{3-4}$ 
$\mathrm{Na}$ avaliação inicial desses casos, a realização de TC de crânio possui papel fundamental para determinação da entrada, localização e trajetória do projétil e na determinação das lesões intracranianas associadas. ${ }^{5}$

As lesões primárias ao TCE são aquelas ocorridas no momento do trauma, as lesões secundárias ocorrem devido à hipóxia, distúrbios metabólicos ou hidroeletrolíticos e hipertensão intracraniana. ${ }^{6}$

Fratura frontal com afundamento de crânio está frequentemente relacionada ao trauma de alta energia e impacto direto, sendo a maioria aberta, havendo comunicação entre o crânio e o couro cabeludo, podendo haver desalojamento de fragmentos ósseos ou cavalgamento de estruturas. Os fragmentos e as bordas dos ossos cranianos facilmente laceram a dura-máter adjacente, podendo lesar os seios venosos, justificando o achado de sangramento abundante proveniente do seio sagital superior na paciente. Além disso, cria-se uma fístula liquórica, gerando risco de infecção do sistema nervoso central. ${ }^{7}$

A paciente apresentou contusão cerebral, composta por áreas hemorrágicas ao redor de pequenos vasos e tecido cerebral necrótico. Os mecanismos de formação das contusões podem ser decorrentes da agressão direta ao parênquima, como no caso das fraturas com afundamento craniano, ou pelo movimento do encéfalo dentro da caixa craniana, que pode levar ao esmagamento do parênquima contra a base do crânio ou outras estruturas rígidas. ${ }^{6}$ Em sua fase aguda, a contusão aparece na TC como áreas corticais hipoatenuantes (componente não hemorrágico) podendo ou não conter zonas focais hiperatenuantes (componente hemorrágico agudo). O componente hemorrágico tende a se expandir em cerca de $24-48 \mathrm{~h}$ às áreas inicialmente não hemorrágicas. $^{8}$

Uma vez estabelecida a lesão, forma-se uma área de edema ao seu redor, que pode crescer durante vários dias e gerar importante efeito de massa. ${ }^{6}$ A hipertensão intracraniana (HIC) tem como uma das causas mais desafiadoras o edema, gerando aumento do volume encefálico em relação ao espaço das vias de circulação do líquor. ${ }^{6}$ É evidenciado pela TC através do apagamento difuso das cisternas e dos sulcos do córtex cerebral, da diminuição volumétrica do sistema ventricular e da hipoatenuação difusa do parênquima cerebral, havendo perda da diferenciação entre substância branca e cinzenta, como apresentado pela paciente. ${ }^{8}$

Quanto à conduta, vítimas de TCE por PAF com Glasgow $\geq 5$ devem ser tratados de forma cirúrgica. Há vantagem no tratamento cirúrgico quando há edema cerebral difuso, como o descrito no caso. Um dos tratamentos preconizados é a craniectomia descompressiva. ${ }^{9}$ A literatura descreve distintas abordagens no caso de lesão dos seios venosos do cérebro, que consistem no reparo ou no sacrifício do seio lesado a fim de manter a hemostasia. Lesões do terço anterior do seio sagital superior, como relatado, podem ser tratadas por meio do tamponamento através de agentes hemostáticos, seguido de suspensão dural, o que foi realizado. $^{10}$

\section{Conclusão}

A elevada incidência de TCE por PAF em nosso meio, associada à complexidade da abordagem dos casos e elevada morbimortalidade, demonstra a importância de discutir tal tema, com o intuito de avaliar conceitos e condutas adotadas.

\section{Referências}

1. Freitas PEP, Bonatelli APF (2000) Lesões craniencefálicas por projétil de arma de fogo fatores de avaliação da mortalidade. J Bras Neurocirurg 11(3):89-105.

2. Aguiar DE (2013) Traumatismo cranioencefálico por projétil de arma de fogo: experiência de 16 anos do serviço de neurocirurgia da Santa Casa de São Paulo. Rev. Col. Bras. Cir 40(4):300-304.

3. Associação Brasileira de Psiquiatria (2014) Suicídio: informando para prevenir. [Internet]. Brasília, DF: ABP [cited 2020 Mar 3]. 52 p. Available from: https://www.hsaude.net.br/wpcontent/uploads/2020/09/Cartilha-ABP-

Preven\%C3\%A7\%C3\%A3o-Suic\%C3\%ADdio.pdf.

4. Ministério da Saúde, Secretaria de Atenção à Saúde, Departamento de Ações Programáticas Estratégicas (2017) Agenda de Ações Estratégicas para a Vigilância e Prevenção do Suicídio e Promoção da Saúde no Brasil: 2017 a 2020. [Internet]. Brasília, DF: MS [cited 2020 Mar 3]. 36 p. Available from: https://www.neca.org.br/wpcontent/uploads/cartilha_agenda-estrategicapublicada.pdf.

5. Sociedade Brasileira de Neurocirurgia (2004) Traumatismo Craniencefálico Moderado e Grave por Ferimento por Projétil de Arma de Fogo: Diagnóstico e Conduta. [Internet]. [cited 2020 Mar 4]. 15 p. Available from: https://diretrizes.amb.org.br/_BibliotecaAntiga/trau matismo-craniencefalico-moderado-e-grave-por- 
ferimento-por-proj\%C3\%A9til-de-arma-de-fogodiagnostico-e-conduta.pdf.

6. Andrade AF, et al (2009) Mecanismos de lesão cerebral no traumatismo cranioencefálico. Revista da Associação Médica Brasileira 55:75-81.

7. Guimarães ACR, et al (2013) A abordagem da fratura do crânio com afundamento. Revista Médica de Minas Gerais 23(5):2-6.

8. Gattás GS (2011) Imagem no traumatismo craniano. Rev Med São Paulo 90(4):157-168.

9. Faleiro RM, et al (2005) Craniotomia descompressiva para tratamento precoce da hipertensão intracraniana traumática. Arq Neuropsiquiatria 63(2-B):508-513.
10. Davidson L Armonda RA (2015) Management of Venous Sinus Injuries. [E-book on the Internet]. New York: Thieme Medical Publishers [cited 2020 Mar 3]. 153-168. Available from: https://www.thiemeconnect.de/products/ebooks/book/10.1055/b-003121745. doi: 10.1055/b-003-121745

Autor para correspondência Gabriela Baltar Ferreira Gomes gabrielabaltar96@gmail.com

Recebido:25/09/2020 Aceito: 15/11/ 2020 